\title{
Identificando Influências na Escolha de uma Graduação em Exatas: um Estudo Qualitativo e Comparativo de Gênero
}

\author{
Maysa M G Macedo ${ }^{1}$, Andrea Britto Mattos $^{1}$, Marisa Vasconcelos ${ }^{1}$, \\ Alexandre Martinazzo ${ }^{2}$, and Roseli Lopes ${ }^{2}$ \\ ${ }^{1}$ IBM Research \\ ${ }^{2}$ Escola Politécnica - Universidade de São Paulo \\ \{abritto, mmacedo, marisaav\}@br.ibm.com, \{am,roseli\}@lsi.usp.br
}

\begin{abstract}
This paper describes preliminary results of a qualitative study conducted with men and women employed at a technology company. Four focus groups were conducted with a twofold goal: (i) to identify the most relevant influences that the selected people received when opting for an undergraduate program in the technology field; and (ii) to verify if these factors differ between the male and female professionals. Our observations indicate that the career decision process differs between the genders: while men seek mainly for personal and financial satisfaction, women tend to demonstrate a higher concern with their decision before family and society.
\end{abstract}

Resumo. Esse artigo descreve resultados preliminares de um estudo qualitativo conduzido com homens e mulheres empregados em uma empresa na área de tecnologia. Foram conduzidos quatro grupos focais com dois objetivos principais: (i) identificar as influências mais relevantes que as pessoas selecionadas receberam no momento em que optaram por um curso superior na área de tecnologia; e (ii) verificar se esses fatores diferem entre profissionais do sexo masculino e feminino. Nossas observações indicam que o processo da escolha de uma carreira difere entre os gêneros: enquanto homens buscam especialmente satisfação pessoal e financeira, mulheres demonstram uma maior preocupação a respeito da sua decisão perante à família e sociedade.

\section{Introdução}

A crescente queda da presença de mulheres em carreiras de Exatas tem levado ao desenvolvimento de muitos trabalhos que tentam entender e explicar o que fazem mulheres escolherem um curso superior na área. Nesse contexto, Cheryan et al. [Cheryan et al. 2015] sugere que meninas desistem de uma possível carreira em Exatas já na infância e aponta questões sociais para o afastamento de mulheres das áreas de Computação e Engenharias, descrevendo uma análise psicológica desde a infância. Já Nakamura et al. [Nakamura and Almeida 2017] tenta explicar as influências na escolha da profissão para meninas na fase do Ensino Médio e Beaubouef et al. [Beaubouef and Zhang 2011] elaborou um estudo qualitativo questionando alunas de um curso superior em Ciência da Computação sobre como elas veem a ausência de mulheres nessa área.

Muitos dos estudos correlatos focam em questionar alunas quanto a intenção delas a respeito da carreira que pretendem seguir. Diferentemente destes, selecionamos uma 
amostra de participantes que já haviam optado por uma carreira em tecnologia - e não evadiram durante a graduação - e focamos no momento da decisão dessas pessoas por um curso superior na área. Além disso, enquanto a maior parte dos trabalhos anteriores coletou somente impressões de mulheres, nosso estudo abordou também homens, com o objetivo de fazer uma análise comparativa de gênero, a fim de verificar se esses fatores decisivos variam entre homens e mulheres. Apesar da amostra limitada, foi possível destacar algumas diferenças relevantes que serão descritas a seguir.

\section{Metodologia}

Para esse trabalho, foram realizados quatro grupos focais compostos por funcionários e estagiários de uma empresa de tecnologia, totalizando 17 participantes que optaram por um curso superior na área de Exatas e seguem carreira no campo de tecnologia. Dois grupos focais foram conduzidos em São Paulo de maneira totalmente presencial, e os outros dois contaram com participantes divididos remotamente entre São Paulo e Rio de Janeiro. Todos os participantes foram convidados por e-mail e participaram por vontade própria, sem receber nenhum incentivo financeiro. Cada pessoa envolvida assinou um termo de consentimento antes do começo do estudo, que garantia que as informações capturadas durante a dinâmica - via gravação de áudio - seriam usadas somente para fins de pesquisa. Os grupos focais tiveram duração média de uma hora e as sessões foram separadas por gênero, sendo dois grupos compostos por mulheres (com 4 e 5 participantes cada) e dois grupos compostos por homens (com 4 participantes cada).

Nove mulheres participaram do estudo, sendo uma da região Nordeste do Brasil e 7 do Sudeste, além de uma participante nascida na Espanha. Dentre os homens, 2 são da região Sul do Brasil, 2 do Nordeste e 4 do Sudeste, totalizando 8 participantes. No momento do estudo, todos os participantes haviam concluído o curso superior em áreas como Ciência da Computação, Sistemas de Informação, Engenharia e correlatos - com exceção de duas estagiárias que estavam no final da graduação. Como alguns participantes preferiram não informar a faixa etária e usamos uma amostra pequena, optamos por omitir essa informação para evitar que os participantes possam ser identificados.

Os grupos focais foram conduzidos por três moderadoras, cujo papel era tomar notas e direcionar a discussão para o objetivo do estudo (destacar os fatores que haviam influenciado os participantes previamente na escolha de um curso superior na área de Exatas). Para iniciar a conversa, foi utilizado um roteiro contendo os seguintes tópicos:

- Apresentação geral: cada pessoa na sala diz a idade, onde nasceu, onde cursou o Ensino Médio e a graduação, além do nome do curso escolhido.

- Antes de ingressar no curso superior, você chegou a ter algum contato (curso técnico/projeto em feira de ciências) com a área de seu curso?

- Quais foram os fatores decisivos para você escolher sua carreira?

- Existiu algum fator contra sua decisão de fazer um curso em tecnologia?

- Qual era sua impressão sobre seu curso antes de entrar na faculdade?

A partir dessas perguntas iniciais, os participantes foram espontaneamente descrevendo quais fatores e experiências foram relevantes para a tomada de decisão. Tanto homens quanto mulheres participaram de forma intensa e receptiva. 


\section{Observações}

Após a transcrição e análise do áudio coletado, agrupamos as experiências reportadas pelos participantes e identificamos os fatores positivos e negativos derivados do grupo focal. Esses fatores são consolidados na lista abaixo e sua ocorrência dentre os participantes é exibida na Figura 1.

Fatores positivos identificados nos grupos focais:

- F1: Opinião positiva da família.

- F2: Presença de um(a) professor(a) de Exatas influente durante o Ensino Médio.

- F3: Presença de uma "pessoa modelo" na mídia e/ou família.

- F4: Interesse em um curso desafiador.

- F5: Reputação negativa dos alunos de cursos superiores de Humanas.

- F6: Presença de computador em casa durante a infância.

- F7: Boa impressão sobre salários/mercado de trabalho na área de tecnologia.

- F8: Hábito de ler livros e/ou assistir a filmes de ficção científica.

- F9: Interesse por jogos de computador e/ou videogame.

- F10: Experiência em curso técnico na área de tecnologia.

- F11: Experiência profissional e/ou estágio na área de tecnologia.

Fatores negativos identificados nos grupos focais:

- FN1: Opinião negativa da família.

- FN2: Opinião negativa dos amigos.

- FN3: Fato das classes serem compostas majoritariamente por homens.

- FN4: Reputação negativa dos alunos com aptidão em Exatas na escola.

- FN5: Má reputação dos cursos de Exatas (matérias difíceis e falta de vida social).

- FN6: Ausência de informação e/ou estímulo no colégio para a área de Exatas.
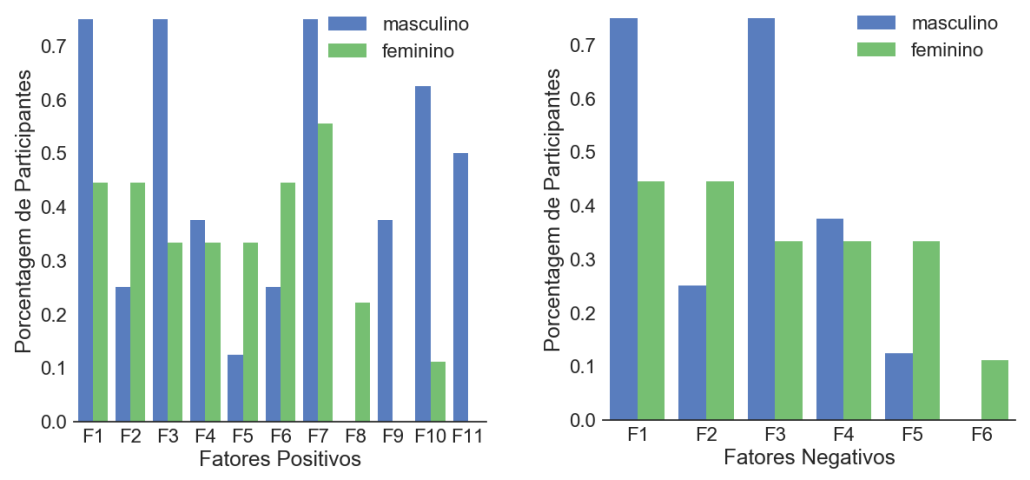

Figura 1. Frequência em que os fatores positivos e negativos identificados impactaram os participantes do estudo, agrupados por gênero.

\subsection{Discussão}

Durante a dinâmica, foram observados mais fatores positivos do que negativos, o que é esperado dado o perfil da amostra de participantes, que optaram efetivamente por um curso superior na área de Exatas. Alguns dos fatores mencionados reforçam descobertas feitas em estudos anteriores, como a importância da estabilidade financeira na decisão da carreira para homens [Fundación de Sadozky 2013] e a influência negativa da família e amigos para mulheres [Nakamura and Almeida 2017]. 
Além disso, no nosso estudo, a maioria dos participantes do sexo masculino mencionou os seguintes fatores como decisivos para a escolha do curso superior: a opinião da família, a presença de uma pessoa modelo na área e a expectativa de boa remuneração (F1, F3 e F7, respectivamente). No caso das participantes do sexo feminino, a boa remuneração (F7) e a opinião da família (F1) também foram decisivos, mas elas destacaram também: a presença de um professor na área de Exatas (F2) e o contato com computador em casa (F6).

Quanto aos fatores positivos, observamos ainda que, na nossa amostra, a presença masculina foi essencialmente superior em cursos técnicos e estágios: apenas uma participante reportou ter realizado um curso de tecnologia. Além disso, quase a totalidade das pessoas citadas como modelo foi o pai ou irmão mais velho dos participantes, evidenciando a ausência de uma figura feminina no processo de decisão. Notamos ainda que a figura paterna exerce influência na carreira que os(as) filhos(as) irão escolher, enquanto a figura materna desempenha um papel de apoiadora, mais do que influenciadora.

Com relação aos fatores que desestimularam a escolha por uma carreira em Exatas, notamos que os homens mencionaram uma quantidade de influências negativas muito menor em comparação às mulheres. Nesse aspecto, destacamos especialmente o fator FN6, posto que muitas participantes apontaram a ausência de suporte da escola para a escolha de uma carreira em Exatas. De todo modo, as influências negativas sugerem não ter sido decisivas para a escolha de carreira da amostra considerada, já que os participantes trabalhavam na área de Exatas no momento da realização dessa pesquisa.

\section{Considerações Finais}

Como recomendação, nosso estudo sugere que as escolas busquem estimular mais as alunas a seguir a carreira de Exatas, através de atividades envolvendo empresas e programas científicos (por exemplo, feiras de ciências). Destacamos especialmente a importância de trazer exemplos femininos, por meio de filmes e palestras, dado que essa forma de estímulo pareceu ausente nos grupos focais que conduzimos.

Como trabalho futuro, pretendemos conduzir um estudo quantitativo para validar se as influências apontadas nesse estudo preliminar são observadas em uma amostra mais significativa e abrangente de pessoas. Também pretendemos verificar se as influências negativas listadas aqui foram impeditivas para pessoas que não seguiram carreira em Exatas.

\section{Referências}

Beaubouef, T. and Zhang, W. (2011). Where are the women computer science students? Journal of Computing Sciences in Colleges, pages 14-20.

Cheryan, S., Master, A., and Meltzoff, A. N. (2015). Cultural stereotypes as gatekeepers: Increasing girls' interest in computer science and engineering by diversifying stereotypes. Frontiers in Psychology, 6(FEB):1-8.

Fundación de Sadozky (2013). Y Las Mujeres...¿Dónde están? http://www . fundacionsadosky • org • ar. Online, accessed 16 May 2018.

Nakamura, F. and Almeida, T. (2017). Hora do Vestibular : o que as estudantes do ensino médio almejam fazer? In Proceedings of Women in Information Technology (WIT) Sociedade Brasileira de Computação. 